\title{
HERANÇA DIGITAL: A REVERBERAÇÃO DE UMA NEÓFITA REALIDADE NO ORDENAMENTO JURÍDICO PÁTRIO
}

\author{
DIGITAL HERITAGE: THE REVERBERATION OF A NEOPHYTE REALITY IN THE
} HOMELAND LEGAL SYSTEM

Clara Angélica Gonçalves Cavalcanti Dias

Graduação em Direito pela Universidade Tiradentes (2001), pós-graduação lato-sensu (especialização - presencial) em Direito pela Escola Paulista da Magistratura (2004), Mestrado (2006) e Doutorado (2010) em Direito pela Pontifícia Universidade Católica de São Paulo. Advogada no Escritório Laura Figueiredo Advogados \& Consultores especializada nas Áreas de Direito Civil e Imobiliário.

Raquel Torres de Brito Silva

Mestranda em Direito (Pós-Graduação Stricto-Sensu) pela Universidade Federal de Sergipe (UFS), São Cristóvão-SE, Brasil. Advogada, Membro da Comissão de Defesa dos Direitos dos Animais (CDDA) da OAB/SE. Especialista (Pós-Graduação Lato Sensu) em Advocacia Pública pela Universidade Cândido Mendes (UCAM), Rio de Janeiro-RJ, Brasil. Bacharel em Direito pela Faculdade de Administração e Negócios de Sergipe (FANESE).

\section{Resumo}

Como fruto da insofismável evolução societária e, adentrando-se na realidade notória do ordenamento jurídico pátrio, é possível contemplar o clamor social em decorrência do reconhecimento legislativo de um direito que ganha acentuado destaque: á herança digital. Pelo exposto, qual é a relevância do direito á herança digital no cenário pátrio? Mister se faz ressaltar que o objetivo cerne da presente pesquisa será o de explanar algumas salutares considerações sobre a sucessão digital e suas principais peculiaridades e implicações hodiernas, de modo a demonstrar sua importância como fruto de uma sociedade hipermoderna que encontra-se em constante evolução e que necessidade de regulamentação expressa e defesa em torno da temática. Abordam-se as técnicas de ponderação e interpretação extensiva nos casos dos conflitos do direito á privacidade do falecido vs. o direito a sucessão digital dos herdeiros sucessores. Ademais, concluiu-se que, alguns projetos de lei (PL), a exemplo da $\mathrm{PL} \mathrm{n}^{\circ}$ 4.099/2012, tendem a adaptar a realidade pátria a essas novas exigências. Todavia, a herança digital e sua defesa concreta ainda carecem da devida regulamentação em prol de cristalizar sua previsão efetiva. Acerca da relevância desse assunto, são fomentados breves 
apontamos com o uso de doutrinas, monografias e artigos que tratam dos pontos em apreço, utilizando-se, para atingir o presente fim, o método dedutivo-qualitativo.

Palavras-chave: Evolução Social. Direito. Herança Digital. Hipermodernidade.

\begin{abstract}
As a result of the inseparable societal evolution and, entering into the notorious reality of the homeland legal system, it is possible to contemplate the social outcry as a result of the legislative recognition of a right that gains accentuated prominence: the digital heritage. Therefore, what is the relevance of the right to digital inheritance in the homeland scenario? It is important to point out that the main objective of this research will be to explain some healthy considerations about digital succession and its main peculiarities and implications today, in order to demonstrate its importance as the fruit of a hypermodern society that is in constant evolution and the need for express regulation and defense around the theme. The techniques of weighting and extensive interpretation in cases of conflicts of the right to privacy of the deceased vs. the right to digital succession of the heirs. Furthermore, it was concluded that some bills (PL), like PL no. 4,099/2012, tend to adapt the homeland reality to these new requirements. However, the digital inheritance and its concrete defense still lack the proper regulation in order to crystallize its effective prediction. Regarding the relevance of this subject, we briefly point out the use of doctrines, monographs and articles that deal with the points under consideration, using the deductive-qualitative method to achieve the present purpose.

Key-words: Social Evolution. Law. Digital Heritage. Hypermodernity.
\end{abstract}

\title{
1. CONSIDERAÇÕES INICIAIS
}

Com as notórias mudanças de paradigmas, a sociedade hipermoderna encontra-se em constante evolução. Novos direitos e clamores exigem cada vez mais uma resposta célere do legislador com a consequente previsão no direito positivo.

Todavia, são notórias as lacunas a serem completadas pelo Poder Judiciário, nos eventuais litígios advindos dessas situações, bem como pelo Poder Legislativo, quanto às previsões expressas e respectivas atualizações dos textos normativos.

Esta supracitada problemática em torno do assunto demonstra a necessidade latente de reforçar o clamor social em prol do acompanhamento das evoluções modernas dos seus direitos pelo legislador brasileiro.

É nesse contexto que insurge a insofismável relevância do direito a herança digital, perpassando pelos aspectos sucessórios e patrimoniais. Contempla-se aqui o direito dos herdeiros em terem acesso aos bens digitais deixados pelo de cujus, provendo-Ihes destinações, com viés econômico ou não. 
Sendo tal tema desprovido de contemplação expressa pela legislação brasileira, é forçoso reconhecer a preocupação de alguns projetos de lei, ainda em trâmites, em torno de sua abrangência.

Nesse prisma, um dos principais obstáculos ao reconhecimento da sucessão digital se dá pelo conflito entre o direito de herança digital dos sucessores e o direito á privacidade do falecido, bem como o resguardo dos seus dados pessoais que, inclusive, podem comprometer terceiros.

Nessa linha de raciocínio ora explanada, qual é a relevância do direito á herança digital no cenário pátrio? Busca-se, com a presente pesquisa, explicar sobre a sucessão digital e as suas principais peculiaridades, de modo a demonstrar sua importância como fruto de uma sociedade hipermoderna que encontra-se em constante evolução.

Almejando-se a viabilidade jurídica em torno do reconhecimento dos bens armazenados virtualmente pelo falecido como componentes do patrimônio dos seus herdeiros, gerando assim a Herança Digital, mister se faz abordar os principais entendimentos doutrinários em torno da temática em apreço.

Para o alcance de tal pretensão maior, o acervo bibliográfico dessa pesquisa é composto por referências doutrinárias, monografias e artigos em torno do assunto, utilizando-se o método dedutivo-qualitativo, partindo-se de uma análise macro para micro da temática.

\section{REFLEXÕES PRELIMINARES SOBRE A SUCESSÃO DIGITAL, SEU CONCEITO E RELEVÂNCIA, NA SOCIEDADE HODIERNA}

No cenário hodierno, fruto do Constitucionalismo contemporâneo, nem sempre a evolução de direitos é acompanhada pelo legislador pátrio, apesar de suas notórias tentativas em atualizar determinadas linhas de raciocínio consoante uma interpretação mais extensiva. Nesses moldes, a doutrina e a jurisprudência corroboram no robustecimento, embora gradativo, das novas necessidades frente à modernização.

Nesse prisma, um forte e notório exemplo, já há muito tempo presente no ordenamento jurídico pátrio, diz respeito à herança digital. Tal assunto engloba os direitos sucessórios, direitos de herança, direitos fundamentais e de privacidade do de cujus e de terceiros (cujos dados podem ser comprometidos e expostos contra a sua vontade). 
Convém a titulo preliminar reconhecer que com o forte avanço tecnológico, caracterizador dessa sociedade hipermoderna, "os documentos físicos estão caindo em desuso nesse novo momento vivido por todas as pessoas. Na atualidade a grande maioria dos produtos, serviços e contratos são oferecidos sem a utilização do papel" (CALDAS; MORAIS, 2019, p. 10).

Isso demonstra que a sociedade hipermoderna torna cada vez mais os documentos e negócios físicos obsoletos, priorizando a utilidade tecnológica e virtual para sua vida pessoal, acadêmica, profissional e, inclusive, para relacionamentos.

O desenvolvimento tecnológico com sua derradeira multiplicação de mecanismos em prol de recolher, armazenar, processar e utilizar as informações, nessa realidade de "massificação das relações contratuais, acabam por estimular um aumento exponencial do fluxo de dados na sociedade contemporânea. Tais informações passam gradativamente a ser utilizadas no tráfego social para as finalidades mais variadas" (SCHREIBER, 2013, p. 135).

É nesse contexto, por exemplo, que as redes sociais obtêm grande espaço na "publicação e compartilhamento de informações de instâncias variáveis, propostas a diferentes públicos que utilizam esses canais e procuram elementos de interesse particular" (PETRY, 2019, p. 47).

Perpassando por essas considerações preliminares, convém destacar que o alvo da Herança Digital, abordagem da presente pesquisa, "não é mudar o âmbito sucessório e sim adequá-lo a realidade da imersão virtual em que se encontra a sociedade, por isso, o escopo é trazer ao ordenamento o conceito de bens virtuais e sua utilização" (CALDAS; MORAIS, 2019, p. 1).

Decerto que o direito à herança possui peculiaridades que merecem apreço, estando "muito ligado a questões patrimoniais, se referindo àquilo construído ou conquistado pelo sujeito em vida, e que quando de sua morte será utilizado para sustento de sua família, daí a grande conexão com o direito à propriedade" (MAGALHÃES, 2018, p. 60).

O direito a herança envolve em seu cerne a possibilidade dos sucessores em dispor dos bens digitais, de valor econômico ou não, do de cujus. Contudo a problemática consiste no conflito de direitos desses sucessores á herança com a privacidade do falecido (e dos terceiros que de certa forma serão expostos pelo histórico pessoal daquele).

Assim sendo, podemos sucintamente definir esses "bens digitais" como 
aqueles "que não podemos ver a olho nu, necessitando para tal da intermediação de um computador ou outro meio semelhante, visto que se trata de uma sequência de bits, e que somente por meio da máquina torna-se possível sua visualização" (MASCARELLO; GIOTTI, 2017, p. 4).

A Herança Digital, pelo exposto, "tem sua importância no âmbito sucessório pela abrangência da utilização das redes sociais e das ferramentas de armazenamento, necessitando, portanto, de uma proteção na esfera jurídica" (CALDAS; MORAIS, 2019, p. 3).

É nesse aspecto que o legislador deve acompanhar a evolução social e a sobrevinda das novas necessidades humanas, sobretudo preservando sua dignidade e ponderando adequadamente os casos práticos com seus persistentes conflitos de direitos.

Na realidade pátria, apesar do atual diploma civil se encontrar desatualizados quanto a algumas questões, o legislador não se preocupou em incluir como herança os comentados bens digitais. Isso pode ser justificado na medida em que, outrora, ainda não se falava em um acervo digital e nos respectivos direitos sucessórios provenientes disso, como se contempla comumente na Modernidade (MASCARELLO; GIOTTI, 2017).

A herança digital, fruto dessa evolução social e da realidade notória do ordenamento jurídico pátrio, resguarda os direitos sucessórios dos herdeiros. Estes podem dar continuidade às relações jurídicas que eram preexistentes, adquiridas e compactuadas antes pelo de cujus. O "histórico virtual" do falecido não precisaria necessariamente ser extinto em virtude do seu óbito (CALDAS; MORAIS, 2019).

Desse modo, podemos extrair que "algumas relações jurídicas perpassam essa fase de extinção da vida, exatamente por haver um legado de bens e de administradores, tornando possível a manutenção do vínculo antecedente" (CALDAS; MORAIS, 2019, p. 7).

Entrementes, a sucessão de bens digitais representa um tema já de grande relevância na sociedade atual (trazendo, por sua vez, casos emblemáticos a serem decididos pelos juízes) (MASCARELLO; GIOTTI, 2017).

Logo, "o crescimento desenfreado da tecnologia, a virtualização da sociedade, a modernização da interação entre os seres humanos, são fatores que sobremaneira contribuem para que o tema ganhe grandes repercussões pelo mundo todo" (MASCARELLO; GIOTTI, 2017, p. 14). 
Após o evento da morte, forçoso se faz reconhecer que os familiares do falecido não possuem ainda um aparo definitivo quanto ao destino dos arquivos nas plataformas virtuais, nas redes sociais e nos e-mails do de cujus. Essa realidade permite que, na maioria das vezes, informações e dados importantes dele sejam desconhecidos (CALDAS; MORAIS, 2019).

Com esse neófito assunto, muitas das plataformas virtuais não sabem ao certo como proceder. Consequentemente fornecem rasas opções aos familiares ainda "incipientes e sucintas, visto que se restringem à possibilidade de exclusão daquela conta ou a 'transformação em memorial', sendo ainda algo muito tímido e que precisa de uma maior explanação no âmbito da Internet" (CALDAS; MORAIS, 2019, p. 13).

Outro forte desafio, em torno do assunto em apreço, consiste em demonstrar a possibilidade da sucessão dos bens digitais que foram acumulados em vida pelo de cujus. Destaque-se a divergência doutrinária quanto a esses bens serem patrimoniais ou meramente afetivos (MASCARELLO; GIOTTI, 2017).

Em face de todo o exposto, se torna importante destacar, embora brevemente, acerca dos dois tipos de sucessão existentes: a sucessão post mortem e a sucessão testamentária.

No que tange a primeira, esta se mostra crescentemente relevante no na medida em que nela se encontram "os embaraços para a transmissão dos ativos digitais deixados pelo de cujus. Quanto à última, mostra-se mais simplória sua resolução, visto que há documento legal expressando a vontade do falecido" (MASCARELLO; GIOTTI, 2017, p. 2).

Nesses termos, a Herança Digital ultrapassa o conceito de mero "conteúdo de comunicações privadas". Sendo assim, "o instituto refere-se a muito mais que as redes sociais, trazendo a possibilidade de a família ter acesso a um acervo de patrimônio e não a intimidade da pessoa falecida" (CALDAS; MORAIS, 2019, p. 25).

Todavia, demonstrar uma efetiva viabilidade da sucessão dos bens digitais acumulados em vida pelo individuo, por meio da sua sucessão hereditária ou sucessão testamentária, constituem outro fator preocupante em torno da aceitação dessa temática. Com isso, talvez o caminho mais adequado para o seu reconhecimento e aplicação prática seja a positivação deste direito (MASCARELLO; GIOTTI, 2017).

Pelas explanações precedentes, é forçoso reconhecer que o ordenamento jurídico brasileiro, seus próprios indivíduos e sociedade, precisam evoluir. Consequentemente, em prol da melhor valorização desse assunto em comento, 
necessário se faz desconstruir obsoletas concepções sobre o tema, "para se remontar em uma visão mais moderna do ambiente que a rodeia, quebrando paradigmas, modificando valores e buscando se adaptar as revoluções silenciosas que darão forma a sociedade globalizada" (XISTO, 2018, p. 80).

$\mathrm{Na}$ medida em que estamos inseridos em constantes avanços, o direito deve se adequar as evoluções sociais e aos seus mais neófitos problemas. No que tange ainda a presente abordagem, a seguir serão delineadas concepções relevantes quando a sucessão digital no cenário Brasileiro.

\section{UMA ABORDAGEM DA SUCESSÃO DIGITAL NO CENÁRIO BRASILEIRO}

Como preliminarmente salientado, o Direito Digital ainda é um ramo jurídico novo, "pouco explorado no Brasil e suas normas gerais ainda estão em criação, não havendo doutrina e jurisprudência consolidadas sobre a maioria das ramificações dessa nova área do direito" (CALDAS; MORAIS, 2019, p. 2).

Torna-se cada vez mais necessário reconhecer que o âmbito jurídico se obriga a atualizar-se nos moldes das modernas tecnologias, "se adequando ao que o corpo social necessita. A população está totalmente imersa na rede mundial de computadores e, por isso, regras referentes a todas as ramificações devem ser aplicadas no ordenamento" (CALDAS; MORAIS, 2019, p. 2).

Dessa forma, embora o direito a Herança Digital não tenha ainda regulamentação própria, ou uma simples previsão pelo Código Civil brasileiro em vigência, "a herança digital já é fato" (PETRY, 2019, p. 48) e sua visibilidade concreta na realidade pátria já é notória.

Na medida em que uma parcela do conteúdo proveniente da Internet passa a, gradativamente, possuir um valor econômico ou intelectivo, a discussão proveniente do destino desses bens- após o falecimento de seu proprietário- é emblemático e atual, "visto que, se há qualquer espécie de produção gerando riqueza, seja intelectual ou monetária, devem existir regras que regulem toda e qualquer situação jurídica" (CALDAS; MORAIS, 2019, p. 2).

A Herança Digital, apesar de não ter sua situação regulamentada ou prevista pelo Código Civil brasileiro em vigência, possui, atualmente, seu conteúdo e análise de casos conforme a posição e defesa da doutrina, "não tendo ainda, aplicabilidade nas relações sucessórias" (MASCARELLO; GIOTTI, 2017, p. 2). 
Assim sendo, "a necessidade de atualizar a legislação brasileira surge especialmente da digitalização da sociedade, ou seja, cada vez mais se vive imerso em uma comunidade virtual" (CALDAS; MORAIS, 2019, p. 10). É imprescindível que a legislação acompanhe a evolução social, de modo a não falhar com a sociedade e o ordenamento.

Quanto a presente abordagem, consoante o atual parecer doutrinário, Mascarello e Giottti (2017) ensinam que,

\begin{abstract}
No Brasil, atualmente, a temática da Herança Digital é resolvida por meio de interpretação extensiva das normas que embarcam o Direito Sucessório no diploma civil brasileiro. Nesta senda, é perfeitamente possível a inclusão de bens digitais no testamento redigido pelo indivíduo, sejam os bens suscetíveis ou não de valoração econômica, valendo-se das disposições do Código Civil. Contudo, quando o de cujus não expressa sua última vontade, os bens digitais acumulados em vida pelo indivíduo, acabam não sendo incluídos na partilha. Já quanto aos bens que careçam do atributo econômico, estes deverão ser objeto de ação judicial movida pelos herdeiros, pois dependendo do bem em questão, pode acabar ferindo os direitos de privacidade e reputação do falecido (MASCARELLO; GIOTTI, 2017, p. 14 e 15).
\end{abstract}

Ademais, nos tribunais brasileiros já é possível reconhecer o vasto número de decisões que vislumbram o conteúdo em torno da validade jurídica dos bens digitais deixados pelo falecido.

Como exemplo, contemplamos o julgamento do Agravo de Instrumento $\mathrm{n}^{0}$ 8858911, do relator Desembargador Victor Martim Batschke, em 3 de julho de 2002, na Câmara Civil do Tribunal de Justiça do Paraná, "que manteve decisão do Juiz 'a quo' que determinou a busca e apreensão de arquivos digitais" (MASCARELLO; GIOTTI, 2017, p. 4).

Apesar de casos específicos serem decididos pelos juízes, essa notória ausência de regulamentação específica é o principal fator de discórdias acentuadas em torno do tema (MASCARELLO; GIOTTI, 2017).

Em decorrência disso, segundo ainda os autores supra, os herdeiros são obrigados a ajuizarem ações em prol da posse dos bens digitais do de cujus. Todavia, "as decisões dos juízes nestes casos são díspares, criando às vezes insegurança jurídica para as partes que buscam a posse dos bens digitais deixados pelo de cujus" (MASCARELLO; GIOTTI, 2017, p. 15)

A acumulação de diversos bens digitais, tais como, sites, blogs, direitos sobre músicas, filmes, livros, entre outros, é comumente observado ao decorrer de nossas rotinas pessoais (MASCARELLO; GIOTTI, 2017). 
Logo, a importância em face dos dados inseridos nas redes sociais acaba se tornando tão importante quanto qualquer outro bem físico. Afinal, todos estes exemplos "fazem parte do que se considera como Acervo Digital. Assim, surge a dúvida: o que fazer com estes bens quando a pessoa falece e não declara a sua última vontade?" (MASCARELLO; GIOTTI, 2017, p. 6).

Esta consiste na grande indagação em virtude do assunto em baila, precisando, por conseguinte, da devida análise do Direito Sucessório no Brasil (instituto tratado tanto pelo Código Civil Brasileiro de 2002, no Livro V, quanto pela Constituição Federal de 1988, gozando de status de direito fundamental e previsão no Artigo $5^{\circ}$, inciso XXX, como o Direito de Herança) (MASCARELLO; GIOTTI, 2017, p. $6)$.

Considerando-se, portanto, que ainda o Brasil é desprovido do direito positivado a respeito dessa matéria, a linha interpretativa e argumentativa das correntes doutrinárias se encaminham no sentido de reconhecer que é plenamente possível a transmissão dos bens digitais "acumulados em vida pelo de cujus quando não há expressa manifestação de ultima vontade, especialmente quanto àqueles bens em que se possa atribuir valor econômico" (MASCARELLO; GIOTTI, 2017, p. 12).

Em face dessa ausência de previsão e regulamentação legal, a situação fica restrita ao ajuizamento de consequentes ações pelos herdeiros, em prol da posse dos bens digitais do falecido. Apesar disso, não existem óbice, mas ao contrário: incentivase que as pessoas se conscientizem sobre o assunto, inserindo, assim, no seu testamento as disposições referentes aos seus bens digitais, suscetíveis ou insuscetíveis de valoração econômica (MASCARELLO; GIOTTI, 2017).

Como a legislação brasileira não apresenta restrição para a inclusão destes bens no testamento, "quando alguém o desejar, deverá se ancorar nas disposições expressas do Código Civil Brasileiro, que trata da sucessão testamentária, numa espécie de interpretação extensiva. Neste passo, dispõe o Artigo 1.857 do Código Civil" (MASCARELLO; GIOTTI, 2017, p. 14).

Pelo exposto, mister se faz reconhecer que, atualmente, no ordenamento jurídico pátrio, "não há a legislação referente ao tema, mas também não há nenhum elemento que impeça a eventual inclusão do patrimônio digital" (CALDAS; MORAIS, 2019, p. 27).

Tal realidade na abordagem desse assunto de sucessão digital, no cenário moderno brasileiro, retrata que a ausência de legislação específica sobre o tema 
reflete, por sua vez, na insegurança jurídica emanada do cenário jurídico brasileiro (CALDAS; MORAIS, 2019).

Isso se justifica pelas consequências provenientes da ausência da legislação, existindo, assim, diversas lacunas, "não trazendo respostas para as famílias, e por isso, a pluralidade de soluções que podem ser atribuídas aos casos concretos desestabiliza e desestimula a utilização dessa nova espécie sucessória" (CALDAS; MORAIS, 2019, p. 29).

Forçoso se faz destacar que não é de incumbência apenas da legislação brasileira atingir essa "atualização, mas também deve haver "uma modificação cultural da população, que deverá adaptar-se a necessidade de deixar expressa e declarada sua última vontade quanto a destinação de seu acerco digital” (XISTO, 2018, p. 77).

Pelo exposto, é possível então visualizar que, na medida em que se possibilita aos usuários a oportunidade de expressarem sua vontade- quanto ao uso e transmissão de seus dados, pós morte- é igualmente possível verificar "que a questão de violação a privacidade do morto não mais se sustenta, tendo em vista que o próprio indivíduo escolherá o que, e quem será alvo de sucessão” (XISTO, 2018, p. 77).

A seguir serão tecidas breves apontamentos quanto a um relevante projeto de lei que, dentro do cenário pátrio, busca adequar o assunto em comento à realidade moderna.

\section{O PROJETO DE LEI № 4.099/2012 NO CENÁRIO PÁTRIO: PRETENSÕES, ABORDAGENS E METAS}

No Brasil, apesar da abordagem em torno da ideia da Herança Digital ainda estar em constante crescimento, devemos reconhecer a existência de um projeto de lei, ainda em trâmite, que objetiva à inclusão no Código Civil de dispositivo que permita a então comentada sucessão dos bens digitais (MASCARELLO; GIOTTI, 2017, p. 10).

Nesses moldes, destaca-se então o Projeto de Lei $n^{\circ} 4.099 / 2012$, de autoria do Deputado Federal Jorginho de Mello. Esse projeto atualmente ainda tramita no Congresso Nacional carecendo de aprovação pelo Senado Federal, embora já tenha sido aprovado pela Câmara dos Deputados. Pretende ele alterar a redação do artigo 1.788 do Código Civil de 2002, de modo a incluir os bens digitais na sucessão (MASCARELLO; GIOTTI, 2017).

Assim, permiti-se aos familiares do falecido o acesso derradeiro às suas redes 
sociais e aos e-mails pessoais. Caso aprovado, passará a vigorar com a seguinte redação: "Parágrafo único: Serão transmitidos aos herdeiros todos os conteúdos de contas ou arquivos digitais de titularidade da herança" (MASCARELLO; GIOTTI, 2017, p. 10).

Além do projeto de $n^{\circ} 4.099 / 2012$, destaca-se igualmente o projeto de lei de $n^{\circ}$ 4.847/2012. Ambos buscam acrescentar ao Código Civil a Herança Digital. Contempla-se também o projeto de lei 7.742/2017 que pretende acrescentar ao Marco Civil da Internet algumas disposições referentes a arquivos pós-morte, apesar de não tratar especificamente da Herança Digital. Tais projetos se destacam pela inovação quanto à discussão do tema (CALDAS; MORAIS, 2019, p. 4).

Embora, como já salientado, não haja previsão da herança digital na legislação atual pátria, esta não obsta sua previsão doutrinária quanto ao enquadramento dos citados arquivos digitais como patrimônio. Nesse prisma, protege-se assim todo tipo de bem virtual. Logo, novamente se torna importante ressaltar "o Projeto de Lei e dar ênfase aos bens sem valor econômico que também são importantes no momento da sucessão para a família" (CALDAS; MORAIS, 2019, p. 20).

No que tange ao projeto de lei (PL) em apreço, nos dizeres expressivos de Xisto (2018):

\footnotetext{
Uma vez que verificamos anteriormente que cada empresa disciplina o tema de sucessão de bens digitais de forma diferente, tendo em vista a propositura do PL 4.099/12, possível concluir que esse projeto de lei proporcionará uma alteração para o código civil que pacifica essa questão, de forma que, se sancionado, forçará as empresas a adequar seus termos e políticas as leis brasileiras, vez que teríamos uma lei específica tratando sobre o tema. Eventual negativa do fornecimento dos dados permitiria aos herdeiros pleitear o direito de acesso ao acervo digital, que estaria estampado de forma mais clara em nosso ordenamento jurídico (XISTO, 2018, p. 70).
}

Sendo assim, o entendimento dos juízes, atualmente, têm gerado decisões diversas quanto ao tema, "gerando controvérsias sobre a questão. Esta lei, portanto, supre a falta de normativas legislativas, especificando expressamente um direito para facilitar essa transferência do domínio" (BIGUELINI, 2018, p. 37-38).

Ademais, com esse Projeto de Lei, engloba-se uma justificação crível para esse tema ser abordado devidamente no Código Civil brasileiro. Afinal, a simples existência de casos concretos relacionados ao tema e objeto de controvérsias, já demonstra razão suficiente para que o assunto seja enfim codificado. Assim, "é mais vantajoso que o direito visualize essas situações, regularizando e uniformizando a 
questão antes que grandes conflitos possam vir a acontecer" (CALDAS; MORAIS, 2019, p. 20).

Ressalte-se ainda que este projeto de lei é o ancião no tratamento "especificadamente sobre o assunto de transferências de bens e contas digitais quando do falecimento de uma pessoa" (BIGUELINI, 2018, p. 38).

Pelo exposto, partindo-se da ideia do Projeto de Lei supracitado, na ausência de uma norma geral, os juízes, por sua vez, não uniformizam suas decisões, trazendo ainda mais controvérsias em torno do assunto (pois, em casos semelhantes, algumas decisões podem ajudar ou prejudicar famílias distintas) (CALDAS; MORAIS, 2019).

Desse modo, o tratamento distinto e individualizado consoante caso concreto, pode gerar "uma insegurança jurídica. Deste modo, há a expressa necessidade da lei civil de tratar do tema" (CALDAS; MORAIS, 2019, p. 20).

Nessa linha de raciocínio, torna-se cada vez mais imprescindível o reconhecimento em torno da evolução dessa temática no cenário hipermoderno presenciado.

Apesar da ausência de previsão normativa, algumas redes sociais, convictos da relevância do assunto, já trazem gradativas, embora rasas, previsões nos seus termos de uso, a exemplo do Facebook, conforme será explanado a seguir.

\subsection{SUCESSÃO DIGITAL NO FACEBOOK (SEUS TERMOS E POLÍTICAS) E A GRADATIVA PREVISÃO TEMÁTICA EM OUTRAS REDES SOCIAIS}

Após as noções preliminares outrora expostas, torna-se oportuno destacar aqui, a titulo preliminar, a existência de plataformas e redes sociais, "como o Facebook e o Twitter, que permitem a determinação por parte do usuário de quem proverá e decidirá o que será feito com a conta em questão" (CALDAS; MORAIS, 2019, p. 21)

Assim sendo, as plataformas como Facebook e Twitter trazem a feliz e gradativa possibilidade do usuário determinar um respectivo "sucessor" para sua conta (como ela poderá ser gerida após o falecimento). Isso envolve "desde a conservação de sua página, possibilitando a transformação em um memorial chegando à possibilidade da exclusão do perfil por familiares do falecido, mediante comprovação da morte do titular" (CALDAS; MORAIS, 2019, p. 25).

Todavia, algumas burocracias se tornam necessárias. Logo, para nomear o denominado "contato herdeiro", o usuário interessado deverá ir às configurações da 
rede social, "entrar na aba 'gerenciar conta', e aparece a opção 'seu contato herdeiro', então tem um espaço para que seja colocado o nome da pessoa escolhida (sendo permitido apenas escolher entre os amigos do Facebook)" (MAGALHÃES, 2018, p. 52).

Na medida em que o Facebook é uma rede social, lançada no ano de 2004, fundada por Mark Zuckerberg e pelos cofundadores Eduardo Saverin, Dustin Moskovitz e Chris Hughes, ela foi inicialmente criada como forma de integração dos alunos da Universidade Harvard, "mas com sua popularização e investimentos de empresários, foi expandida para as demais localidades do globo e se tornou uma das redes sociais mais acessadas em todo o mundo" (XISTO, 2018, p. 56-57).

Mister se faz reconhecer, outrossim, que o Facebook é uma das raras redes sociais a dispor de cláusulas em seus termos disciplinando a importante possibilidade de fornecimento de dados, ou de acesso ao perfil do usuário, após sua morte. Assim, "as cláusulas atinentes ao tema, estão originalmente dispostas na seção de disposições adicionais do termo de serviço do Facebook" (XISTO, 2018, p. 57).

Segundo seus termos e políticas, não será possível a transferência de qualquer direito ou obrigações para terceiros "sem o consentimento da empresa, sendo possível, entretanto, nomear uma pessoa que ficará responsável pela administração da conta, uma vez ocorrida a morte de seu titular ou solicitar a remoção do perfil do de cujus" (XISTO, 2018, p. 58).

Pelo exposto, compreende-se que, sendo da vontade da família ou responsável a exclusão do perfil, será então necessário o preenchimento de um formulário, que é disponibilizado pela própria rede social, e também o envio de documentos em prol da respectiva comprovação da morte do usuário e do alegado vínculo de parentesco ou até mesmo da vontade do de cujus "em nomear determinada pessoa como responsável pelos dados ali contidos, conforme podemos perceber nas disposições contidas na central de perguntas do Facebook" (XISTO, 2018, p. 60).

Verifica-se, portanto, que no cenário pátrio, a discussão crescente sobre a possibilidade de acesso dos herdeiros ao perfil no Facebook do falecido, gera, algumas vezes, o conflito entre o direito à privacidade e o direito à herança. Nesses casos, deve-se utilizar a devida técnica da ponderação conforme prévia análise das principais implicações de ambos os direitos no caso concreto (MAGALHÃES, 2018).

Por derradeiro, conforme Magalhães (2018), a conclusão notória sobre esse contexto supracitado leva-nos a perceber a prevalência do direito á privacidade sobre o direito á herança, na maioria dos casos. Isso decorre em virtude dos sentimentos do 
ser humano, indo além de questões meramente patrimoniais.

Assim sendo, "certas informações que possam ser descobertas pela família caso se opte pela violação da privacidade, podem causar uma série de transtornos, e inclusive mudar a própria ideia da dos familiares sobre o falecido" (MAGALHÃES, 2018, p. 61).

Ainda no que tange aos termos e política, nota-se que os dados do usuário ficam à disposição do Facebook. Este, por sua vez, dita as regras de armazenamento e controle destes dados, inclusive "proibindo o compartilhamento da senha ou acesso a terceiros, afirmando sempre que é para uma melhor utilização dos produtos e serviços, e deixando poucas ou nenhuma opção ao usuário que não concorde com certos termos" (MAGALHÃES, 2018, p. 51).

Ademais, no que tange a abordagem da temática por outras redes sociais, no caso de falecimento de um usuário, "o Twitter permite que uma pessoa autorizada a agir em nome do Estado ou um familiar verificado do falecido possa desativar a conta" (MAGALHÃES, 2018, p. 55).

Por sua vez, o Instagram também vem permitindo que qualquer pessoa que "souber do falecimento de um usuário faça uma denúncia para que a conta seja transformada em memorial, contudo, apenas parentes podem solicitar que a conta seja removida da plataforma" (MAGALHÃES, 2018, p. 56).

Já o próprio Google "permite que representantes e familiares fechem a conta da pessoa falecida. Contudo, a principal preocupação é manter seguras as informações do usuário, assim não podem fornecer senhas e outros detalhes de login" (MAGALHÃES, 2018, p. 56).

Logo, em que pese a colisão entre direitos ser tão notório, é possível reconhecer o desenvolvimento do tema por meio dos termos e políticas de algumas redes sociais preocupadas em acompanhar tal evolução social.

Todavia, apontamentos melhores se tornam imprescindíveis a respeito desta exposta colisão que envolve o direito á herança digital no cenário moderno.

\section{COLISÕES DE DIREITOS NA SUCESSÃO DIGITAL: PRIVACIDADE VS. HERANÇA DIGITAL E O CONSEQUENTE USO DA TÉCNICA DE PONDERAÇÃO E INTERPRETAÇÃO EXTENSIVA}

A Constituição Federal no art. $5^{\circ}$, inciso $X$, versou sobre a proteção da 
privacidade, assegurando-a como direito fundamental. Dessa consagração, é possível vislumbrar sua preocupante defesa nos casos de qualquer manifestação íntima que venha a expor a vida privada e da personalidade dos sujeitos envolvidos, conforme cada caso concreto avaliado.

Todavia, em virtude dessa hodierna sociedade digital, uso das redes sociais se torna cada vez mais frequente. Logo, a definição de privacidade vem englobando aspectos diferentes na medida em que a exibição livre da vida pessoal, por parte dos próprios usuários, induz a compartilharem de tudo aquilo que desejam sobre momentos ou até mesmo sentimentos pessoais (CALDAS; MORAIS, 2019).

Presencia-se, portanto, "uma faculdade dos sujeitos, é decisão particular expor ou não alguma notícia ou algum dado referente a si. É a escolha de se tornar público ou não" (CALDAS; MORAIS, 2019, p. 23).

Ao tratar da herança digital, como outrora explanado, reconhece-se o conflito entre direitos: privacidade vs. herança. Ambos conectados à dignidade da pessoa humana, "pois dispõem sobre questões que estão ligadas a uma existência digna do indivíduo, um assegurando a privacidade, e outro assegurando a defesa do patrimônio individual e a manutenção da família" (MAGALHÃES, 2018, p. 61).

Nesses moldes, "o valor da pessoa humana, portanto, sua dignidade, é o limite para a intervenção do Estado ou da sociedade na esfera individual de seus componentes" (BORGES, 2005, p. 146).

Portanto, o verdadeiro papel do princípio da dignidade humana em nosso ordenamento jurídico, consiste em "garantir a emancipação do homem, através do respeito por suas diferenças, do respeito por suas características, por sua consciência e sua faculdade de se autodeterminar conforme seu próprio sentimento de dignidade" (BORGES, 2005, p. 147).

Apesar da tutela sobre a herança digital no Brasil ainda não tenha sido regulamentada, o assunto em torno de repassar a totalidade das contas digitais aos herdeiros, demonstra posições divergente: para alguns, isso pode ser cabível, embora quando "transferir a totalidade dos bens e dos dados inseridos no perfil ou conta de uma pessoa falecida, você pode violar direitos da personalidade de forma póstuma, como por exemplo o direito à privacidade" (XISTO, 2018, p. 70).

No que tange mais precisamente ao Direito à privacidade, para outros doutrinadores, não há o que se falar em herança digital. Considera-se aqui a privacidade do de cujos. Logo, se alguém conseguir acessar as suas redes sociais, 
poderá consequentemente "implicar em muitas outras coisas, tais como a visualização de conversas, imagens e mesmo compras das quais o falecido poderia desejar que continue sem que aqueles as suas voltas saibam" (PETRY, 2019, p. 44).

Nessa arquitetura, a liberdade de manifestação e a privacidade, envoltos nos casos de internet, são consequências diretas da sua própria comercialização (CASTELLS, 2001).

Se comparado a outros direitos da personalidade, a exemplo da honra, o direito à privacidade "é de evolução bem mais recente. Aponta-se como seu marco inicial o artigo The Right to Privacy, publicado em 1890 na Harvard Law Review, revista jurídica da prestigiosa faculdade norte-americana" (SCHREIBER, 2013, p. 134).

Pelo exposto, deve-se entender a privacidade não somente como prezar pela ausência da interferência do Estado na vida do indivíduo, "mas também como o poder de se reivindicar ao Estado a tutela dessa privacidade, protegendo o indivíduo de terceiros" (HIRATA, 2017, p. 4).

Assim, os usuários de redes sociais "precisam estar alerta sobre os perigos de dar informações de caráter íntimo. Dados podem ser utilizados indevidamente, também por meio de hackers ou vírus" (HIRATA, 2017, p. 15).

Por derradeiro, ao reconhecer o direito à privacidade como direito de personalidade, busca-se proteger a esfera privada da pessoa contra a intromissão, "curiosidade e bisbilhotice alheia, além de evitar a divulgação das informações obtidas por meio da intromissão indevida ou, mesmo, que uma informação obtida legitimamente seja, sem autorização, divulgada" (BORGES, 2005, p.163).

É possível, inclusive, reconhecer a dimensão procedimental e substancial da privacidade. O primeiro se exprime "na coleta da informação pessoal. A coleta clandestina ou desautorizada de informações pessoais deve ser repelida" (SCHREIBER, 2013, p. 139).

Por sua vez, a dimensão substancial está "vinculada ao próprio emprego da informação obtida. Toda pessoa tem direito a controlar a representação de si mesma que é construída a partir de seus dados pessoais" (SCHREIBER, 2013, p. 139).

Ademais, ressalte-se que a lei 12.965/2014, que versa sobre o uso da internet no Brasil, conhecida como Marco Civil da Internet, estabelece em seu artigo $3^{\circ}$ que a disciplina do uso da internet no Brasil possui como um dos seus relevantes princípios: "[...] II - proteção da privacidade" (PETRY, 2019).

Por meio dessa legislação, extrai-se, do princípio mencionado, "que o uso da 
internet é respaldado pela proteção da privacidade, e mesmo que a pessoa já tenha falecido, ainda possui tal direito" (PETRY, 2019, p. 44).

Todas estas situações, assim como inúmeras outras, poderiam ser supridas por meio de uma legislação específica sobre o instituto (reforçando-se aqui a necessidade da previsão legislativa sobre o tema). Por conseguinte, isso evitaria decisões tão diferentes em face de situações semelhantes (MASCARELLO; GIOTTI, 2017).

Todavia, é possível reconhecer o uso da analogia e da interpretação extensiva "como forma de suprir a lacuna legislativa, que sem sombra de dúvidas, evitaria a grande quantidade de litígios referentes ao instituto, contribuindo também para desafogar o Poder Judiciário" (MASCARELLO; GIOTTI, 2017, p. 2).

Em face dessa notória colisão de direitos e, em prol de solucionar a colisão entre princípios, utiliza-se comumente, consoante doutrina majoritária, a técnica da ponderação. Assim, tenta-se extrair do caso concreto analisado qual princípio terá prevalência sobre o outro, "e como dito acima, já que as estruturas são semelhantes às dos princípios, a colisão entre direitos fundamentais também pode ser solucionada através da ponderação" (MAGALHÃES, 2018, p. 57).

Pelas lições doutrinárias trazidas, em caso de colisão entre normas constitucionais, deve-se utilizar a teoria da ponderação de valores ou de interesses. Por intermédio dela, resolve-se a colisão entre os direitos, embora o princípio que foi afastado não perca sua validade, mas apenas sua efetividade frente ao caso.

Ademais, em síntese, em prol da resolução das colisões entre normas constitucionais, é possível se utilizar a citada teoria da ponderação de valores; dos princípios de interpretação constitucional e da proporcionalidade e razoabilidade à luz do princípio da unidade e concordância prática entre as normas colidentes (ARAÚJO, 2017).

Como não há hierarquia entre os direitos conflitantes no caso da herança digital, deverá ser então utilizada a técnica da ponderação. O que se busca não é, todavia, dizer que "um destes direitos sempre deverá estar acima do outro, a ideia é que, analisando a questão da privacidade e o direito de herdar dos sucessores, possamos estabelecer qual princípio deveria prevalecer sobre o outro neste caso" (MAGALHÃES, 2018, p. 59).

Pelo exposto, na atual legislação pátria que trata da relação sucessória, devese reconhecer a ausência de qualquer disposição referente à transmissão de bens 
digitais. Diante dessa lacuna positivista, "é necessário buscar respaldo na analogia e na interpretação extensiva, com o fim de possibilitar a transmissão causa mortis dos ativos digitais" (MASCARELLO; GIOTTI, 2017, p. 11).

Deste modo, em face da sucessão digital, é notória a dualidade e o conflito de interesses. Consequentemente isso deve ser amenizado com a criação e promulgação de legislação que, por sua vez, verse sobre alguns limites da Herança Digital, visto que, "sem a temática estar presente no ordenamento, fica muito mais difícil que a sociedade entenda do que se trata o instituto e, nessa esteira, comece a criar uma nova cultura referente à transmissão dos bens virtuais" (CALDAS; MORAIS, 2019, p. 28).

Mister se faz ainda ressaltar que o Direito Digital restringe-se quanto a sua aplicação nos casos de uso da "interpretação extensiva e pelo uso da analogia, tendo em vista que a atividade legislativa na maioria das vezes não é suficiente para acompanhar seu iminente e acelerado crescimento" (MASCARELLO; GIOTTI, 2017, p. 11).

Ademais, do conflito entre o direito dos herdeiros em obter propriedades virtuais e o direito à privacidade do falecido, é possível concluir que "inexistem impedimentos para a implantação da Herança Digital no ordenamento jurídico brasileiro" (CALDAS; MORAIS, 2019, p. 1).

Em que pese o direito à privacidade do de cujus estar ameaçado, deve-se partir do pressuposto "de que nem tudo que está resguardado no computador, por vontade do falecido, deveria ser conhecido pelos seus herdeiros" (CALDAS; MORAIS, 2019, p. 23).

Dessa forma, considerando todo o exposto, é possível extrair mais considerações pertinentes da análise da colisão entre o direito à privacidade e o direito à herança:

\footnotetext{
Ambos os direitos são fundamentais, tanto no aspecto formal quanto no material, porque além de estarem presentes na nossa Constituição Federal, o conteúdo deles está intrinsecamente ligado aos valores de nossa sociedade, então são direitos essenciais. Como não há hierarquia entre eles, deverá ser utilizada a técnica da ponderação, sendo que o que se busca não é dizer que um destes direitos sempre deverá estar acima do outro, a ideia é que analisando a questão da privacidade e o direito de herdar dos sucessores, possamos estabelecer qual princípio deveria prevalecer sobre o outro neste caso (MAGALHÃES, 2018, p. 59).
}

Nessa oportunidade, cabe a doutrina, e as forçosas pressões sociais, 
apresentarem algumas alternativas em prol de sanar eventuais conflitos decorrentes da existência de um acervo digital e do direito à herança quando em derradeiro conflito com o direito à privacidade do falecido.

Nesses termos, consoante às lições de Xisto (2018) seria possível, para resolver tais conflitos, a manifestação de última vontade do titular de um acervo digital através de um testamento, por exemplo. Mas, para isso, é de insofismável relevância a conscientização social em torno disso.

Posteriormente, também seria possível tratar da disponibilização de mecanismos incorporados à própria plataforma digital, possibilitando assim a criação de um testamento digital. Este poderia ser considerado perfeitamente válido, surtindo seus respectivos efeitos da mesma forma que um testamento em papel (XISTO, 2018).

Outra proposta seria a criação de uma exigência, desde que regida por lei, que force tanto as empresas quanto as plataformas digitais a fornecerem ferramentas adequadas "que possibilitem a escolha do usuário em estabelecer a destinação de bens armazenados em seus servidores, de forma a delimitar quais conteúdos poderão ser fornecidos pela empresa em caso da ocorrência da morte de seu titular" (XISTO, 2018, p. 80).

Em análise a todas essas considerações em comento, na medida em que se possibilita aos usuários a oportunidade de expressar sua vontade quanto ao uso e transmissão de seus dados, após sua morte, é "possível verificar que a questão de violação a privacidade do morto não mais se sustenta, tendo em vista que o próprio indivíduo escolherá o que, e quem será alvo de sucessão" (XISTO, 2018, p. 77).

Logo, a questão referente ao acesso dos arquivos pessoais de uma pessoa que faleceu, projeta um conflito com a privacidade dessa pessoa. Engloba-se aqui, portanto, os seus bens digitais, protegidos por senha. Desse modo, "salienta-se a relevância de o autor da herança expressar sua pretensão em testamento quanto ao acesso e utilização de seus bens digitais" (PETRY, 2019, p. 48).

Apesar das sugestões expostas, não estar ainda cristalizado no direito atual o entendimento "quanto à intimidade e privacidade do falecido, assim como, quais serão as proteções referentes aos direitos de sua personalidade que devem perdurar para além do fim de sua vida" (PETRY, 2019, p. 48).

Nessa linha de raciocínio pontuada, a questão referente à herança digital ainda é pouco difundida. Na presente realidade, a população brasileira é desprovida da devida cultura ou preocupação quanto à destinação de seus bens para depois de sua 
morte. Por tais razões, "será necessária também, a implementação de alternativas que possibilitem a manifestação e a proteção do acervo digital e dos direitos da personalidade de um indivíduo, mesmo após a morte deste" (XISTO, 2018, p. 78).

Nessa arquitetura, a inclusão social no meio digital, através da Internet, traz também uma necessidade de adequação jurídica a esta nova realidade dos sujeitos. Sendo assim, "ao dispor de diversos documentos virtuais ou de redes sociais, tornouse imprescindível à presença da Herança Digital que, por sua vez, adequa ao mundo jurídico a possibilidade de transmitir esse patrimônio a qualquer herdeiro legítimo" (CALDAS; MORAIS, 2019, p. 27).

Com a abordagem acerca da herança digital, é forçoso destacar que as novas tecnologias ampliam os Direitos humanos e fundamentais. Tal cenário, inclusive, reverbera a consideração da doutrina constitucional moderna em defender a $5^{\circ}$ geração/dimensão dos direitos fundamentais, vinculados ao uso dessas novas tecnologias e as peculiaridades da era digital (GOULART, 2012).

Logo, na medida em que presenciamos a passagem de uma sociedade industrial para uma sociedade informacional, o contexto do surgimento da $5^{\circ}$ geração traz consigo a abordagem acerca da inclusão digital, embora o grande desafio do espaço virtual seja o uso maciço das novas tecnologias e dos seus dados. É nessa conjuntura que torna necessária a implementação de políticas públicas em prol da educação digital (GOULART, 2012).

Dessa forma, é possível preservar a dignidade, privacidade e o respeito no uso dos dados do falecido, não privando os herdeiros de ter acesso aos bens, dotados ou não de valor econômico, que traz significativa importância na linha sucessória.

O reconhecimento da relevância desse tema se torna cada vez mais notório em face da hodierna sociedade hipermoderna que se encontra em constante evolução. Nesse prisma, deve o legislador pátrio se adequar a realidade latente, fomentando expressamente a defesa em torno desse neófito direito à herança digital.

\section{CONSIDERAÇÕES FINAIS}

Mister se faz concluir que a temática em torno da herança digital ainda perpassa por fortes obstáculos e desafios em torno de sua consequente aceitação na legislação pátria.

Apesar da feliz previsão do assunto por meio de projetos de leis, ainda não se 
pode vislumbrar no campo prático suas reais modificações legislativas.

As discussões em torno do tema estão tomando repercussões acentuadas nos juízos, sendo possível vislumbrar várias decisões dicotômicas para abordar desse igual assunto. Nesses moldes, a revolta dos herdeiros interessados nos bens digitais, providos em não de valor econômico, ganha gradativamente destaque no cenário pátrio.

É possível concluir, portanto, que, nos casos de conflitos entre o direito da herança digital dos sucessores e o direito à privacidade do falecido, deve-se ponderar tais casos com base no caso concreto, sendo igualmente possível o uso de interpretações extensivas em prol de conferir um ou outro direito.

Apesar da dificuldade de regulamentação prática em torno da temática, devese reconhecer que o presente assunto vem tomando repercussões incomensuráveis na Modernidade, clamando por uma efetiva posição do legislador de modo a atualizar-se em face dos novos clamores e direitos sociais. 


\section{REFERÊNCIAS}

ARAÚJO, Rúbia Maria Ferrão de. Liberdade de Expressão na Internet. Direito digital. Íntegra editorial, 2017, p. 43-82.

BIGUELINI, Thais Donato. Herança Digital: Sucessão Do Patrimônio Cibernético. Trabalho de Conclusão do Curso de apresentado em cumprimento às exigências do curso de bacharel em Direito da Universidade Regional do Noroeste do Estado do Rio Grande do Sul. ljuí/RS: 2018. Arquivo Pessoal.

BORGES, Roxana Cardoso Brasileiro. Disponibilidade dos direitos da personalidade e autonomia privada. São Paulo: Saraiva: 2005, p. 111-154 e 162166.

CALDAS, Luana Maria Figueiredo de Lima; MORAIS, Rosângela Maria Rodrigues Medeiros Mitchell de. Herança digital: bens virtuais como patrimônio sucessório. Revista de Estudos Jurídicos do UNI-RN, Natal, n.3, janeiro / dezembro 2019. Arquivo Pessoal.

CASTELLS, Manuel. A Galáxia Internet: Reflexões sobre internet, negócios e sociedade. Tradução de Rita Espanha. Fundação Calouste Gulbenkian, Lisboa, 2001, p. 201-222.

GIOTTI, Giancarlo Barth; MASCARELLO, Ana Lúcia de Camargo. Herança digital. $5^{\circ}$ Simpósio de Sustentabilidade e Contemporaneidade nas Ciências Sociais, 2017. ISSN 2318-0633. Arquivo Pessoal.

GOULART, Guilherme Damásio. O impacto das novas tecnologias nos direitos humanos e fundamentais: o acesso à internet e a liberdade de expressão. Revista Direitos Emergentes na Sociedade Global. v.1, n.1,jan-jun/2012.

MAGALHÃES, Thalita Abadia de Oliveira. A possibilidade de acesso aos dados privados no perfil do facebook de usuário falecido: Colisão entre o direito à privacidade e o direito à herança. Trabalho de Conclusão de Curso apresentado no Curso de Direito na Faculdade de Direito Professor Jacy de Assis da Universidade Federal de Uberlândia. UBERLÂNDIA/MG: 2018. Arquivo Pessoal.

HIRATA, Alessandro. Direito à privacidade. In: Enciclopédia jurídica da PUCSP, tomo II (recurso eletrônico): direito administrativo e constitucional/ coord. Vidal Serrano Nunes Jr. [et al.]- São Paulo: Pontifícia Universidade Católica de São Paulo, 2017.

PETRY, Rodrigo. A tutela do direito à herança digital no ordenamento jurídico pátrio à luz dos direitos da personalidade. Trabalho de conclusão de curso apresentado ao curso de graduação em Direito, da Universidade do Sul de Santa Catarina. Palhoça: 2019. Arquivo Pessoal. 
SCHREIBER, Anderson. Direitos da Personalidade. $2^{\mathrm{a}}$ ed. São Paulo: Atlas, 2013, p. $71-184$.

XISTO, Ana Paula. Herança digital: extensão e tutela da personalidade civil post mortem em harmonia com o direito à privacidade na rede. Monografia apresentada ao Curso de Graduação em Direito, do Centro Universitário Toledo. Centro Universitário Toledo: Araçatuba-SP, 2018. Arquivo Pessoal.

Recebido em 25/08/2020 Aprovado em 19/04/2021 Received in 25/08/2020 Approved in 19/04/2021 